\title{
Variation of Phenolic Content in Globe Artichoke in Relation to Biological, Technical and Environmental Factors
}

\author{
Sara Lombardo, Gaetano Pandino, Rosario Mauro, Giovanni Mauromicale* \\ Dipartimento di Scienze Agronomiche, Agrochimiche e delle Produzioni Animali (DACPA) - \\ Sezione Scienze Agronomiche, Università di Catania \\ Via Valdisavoia 5, 95123 Catania, Italy
}

Received: 14 September 2009. Accepted: 28 October 2009.

\begin{abstract}
In Italy, globe artichoke production is prevailingly concentrated in the South and islands, where it provides an important contribution to the agricultural economy. In recent years, there has been a renewed interest in this crop as a promising source of polyphenols, a heterogeneous class of secondary metabolites characterized by various healthy properties well-documented in literature. The phenolic fraction, present in the different artichoke plant parts, varies widely in relation to biotic and abiotic factors. Therefore, the present study aimed at evaluating the variation of phenolic content in globe artichoke in relation to biological, technical and environmental factors. Two field-experiments were carried out in Sicily (South Italy) in two representative cultivation areas, in order to examine the effects of genotype, head fraction, season conditions, planting density and arrangement on the globe artichoke phenolic concentration. Both the total polyphenols and the individual phenolic compounds detected were notably genotype-dependent. Particularly, the high level of caffeoylquinic acids (chlorogenic acid, among others) and apigenin 7$O$-glucuronide, reported respectively by "Violetto di Sicilia" and "Romanesco clone C3", could be used to encourage globe artichoke fresh consumption. Total polyphenols content also resulted more abundant in specific accumulation sites within the inflorescence, such as the floral stem and receptacle, and for most of genotypes it decreased during the second year in response to the different meteorological conditions. Additionally, total polyphenols content significantly and linearly increased as plant density increased from 1.0 to 1.8 plant $\mathrm{m}^{-2}$ and it significantly increased by $13 \%$ passing from single to twin rows plant arrangement.
\end{abstract}

Key-words: abiotic factors, biotic factors, caffeoylquinic acids, flavonoids, globe artichoke, total phenolics.

\section{Introduction}

Globe artichoke [Cynara cardunculus L. var. scolymus (L.) Fiori] is a herbaceous plant native to the Mediterranean Basin, appreciated since ancient times as a tasty food with therapeutic properties on human health. Today, artichoke heads production is widely diffused all over the world (127 Kha, average data across 2005/07), even if it is concentrated in Southern Europe, with Italy as the leading producer (about $471 \mathrm{Kt}$ per year), followed by Spain and France (about 214 and $51 \mathrm{Kt}$ per year, respectively). Globe ar- tichoke is also cultivated in the Near East, North Africa, South America, United States (California) and recently its cultivation is spreading in China (10 Kha) and Peru (6 Kha) (Faostat, 2009).

The edible part of the plant is the enlarged receptacle and the tender thickened bracts bases of the head (capitulum), which is the immature Compositae (Asteraceae) inflorescence, used worldwide as both a fresh and canned delicacy product. In recent years, an increasing demand by consumers for functional foods has led to a renewed interest in this crop. Indeed, the healthy properties of artichoke extracts (Geb- 
hardt, 1997; Brown and Rice-Evans, 1998) have always been related to the phenolic compounds present in the leaves and the inflorescences, with $O$-diphenolic acids (mono- and di-caffeoylquinic acids) and flavonoids (luteolin and apigenin derivatives) as the major bioactive substances (Lattanzio and Van Sumere, 1987; Wang et al., 2003; Shütz et al., 2004).

Phenolics are a heterogeneous group of phytochemicals normally synthesized both during the regular plant growth and development. Nevertheless, polyphenols synthesis and accumulation in plants may be stimulated in response to biotic and abiotic stresses (Beckman, 2000). The latter modify phenolic composition both qualitatively and quantitatively (Falleh et al., 2008). Enhanced phenolic synthesis under stressful conditions is related to the important role of polyphenols against reactive oxygen species, inevitably produced when aerobic or photosynthetic metabolism is impaired by stresses. Moreover, these biomolecules act in plants as protective screen against UV light, anti-microbial agents, phytoalexins and attractants for pollinators, among others (Naczk and Shadidi, 2006).

In literature, although the effects of some biotic factors, such as genotype and plant parts, has been studied extensively on the phenolic content and qualitative composition of globe artichoke plants, the data published are limited to few genotypes (Alamanni and Cossu, 2003; Curadi et al., 2004), scarcely representative of the gene pool of the subspecies and frequently purchased at local supermarket (Racchi et al., 2002; Brat et al., 2006). Moreover, available data, to our knowledge, are lacking on the influence of abiotic factors on the phenolic amount of artichoke plant. In this light, the aim of the present study was to evaluate the variation of polyphenols content of globe artichoke in relation to some biotic and abiotic factors. Considering that Italy holds the most important germplasm (Mauromicale and Ierna, 2000), we evaluated total polyphenols content in seventeen accessions of globe artichoke, in order to also define their aptitude for specific uses (fresh market, food processing, pharmaceutical applications, etc.). Additionally, the effects of head fraction, season conditions, plant arrangement and density on the total polyphenols content were studied.

\section{Materials and methods}

Two field-experiments were carried out during the growing seasons 2006/07 and 2007/08, following similar criteria for the studied factors.

\subsection{Plant material, experimental design and man- agement practices}

\subsubsection{Trial A: Effects of genotype, head fraction} and season conditions. A two year experimental trial was conducted at the experimental station of Catania University, on Catania Plain $(10 \mathrm{~m}$ a.s.l., $37^{\circ} 25^{\prime} \mathrm{N}, 15^{\circ} 30^{\prime} \mathrm{E}$ ), in a typic and/or vertic xerochrepts soil (USDA, Soil Taxonomy). The Catania Plain is a representative area for globe artichoke cultivation in Mediterranean region. The local climate is semiarid-Mediterranean, with mild winters and hot, rainless summers.

Seventeen globe artichoke accessions (Fig. 1) were manually planted in the form of both semi-dormant offshoots ("ovoli") or seeds (achenes) in August 2006. The plant material was arranged in a randomized block experimental design with 4 replications, using a planting density of 1.0 plant $\mathrm{m}^{-2}$ (equivalent to a within row plant-to-plant spacing of $0.80 \mathrm{~m}$ apart, and a row-to-row spacing of $1.25 \mathrm{~m}$ ). Each experimental unit consisted of 10 plants. A typical fertilizer regime $\left(200 \mathrm{Kg}\right.$ of $\mathrm{N}, 80 \mathrm{Kg}$ of $\mathrm{P}_{2} \mathrm{O}_{5}$ and $100 \mathrm{Kg}$ of $\mathrm{K}_{2} \mathrm{O}$ per ha) was applied, and drip irrigation was provided during the summer, whenever the accumulated daily evaporation reached $35 \mathrm{~mm}$ (equivalent to $100 \%$ of maximum evapotranspiration). Pest control was achieved by standard commercial practices. Gibberellic acid was not supplied to the plants.

The mean 30-year maximum monthly temperature ranges between $14.8{ }^{\circ} \mathrm{C}$ (January) and $30.6{ }^{\circ} \mathrm{C}$ (July) and minimum temperature between $7.8{ }^{\circ} \mathrm{C}$ (January) and $22.3{ }^{\circ} \mathrm{C}$ (August). Figure 2 shows temperatures and rainfall trends recorded during the two-year period. In the second year, between January and April, the climate was characterized by maximum and minimum average temperatures lower than $1.7^{\circ} \mathrm{C}$ $\left(11.4\right.$ vs. $\left.13.1^{\circ} \mathrm{C}\right)$ and $0.6{ }^{\circ} \mathrm{C}\left(3.4\right.$ vs. $\left.4.0^{\circ} \mathrm{C}\right)$ compared to the first year, respectively. By contrast, rainfall level was, on the whole, lower than 134 mm (93 vs. $227 \mathrm{~mm}$ ).

2.1.3 Trial B: Effects of planting density and arrangement. The field-experiment was carried out during the $2006 / 07$, on Gela Plain $\left(37^{\circ} 11^{\prime}\right.$ N 

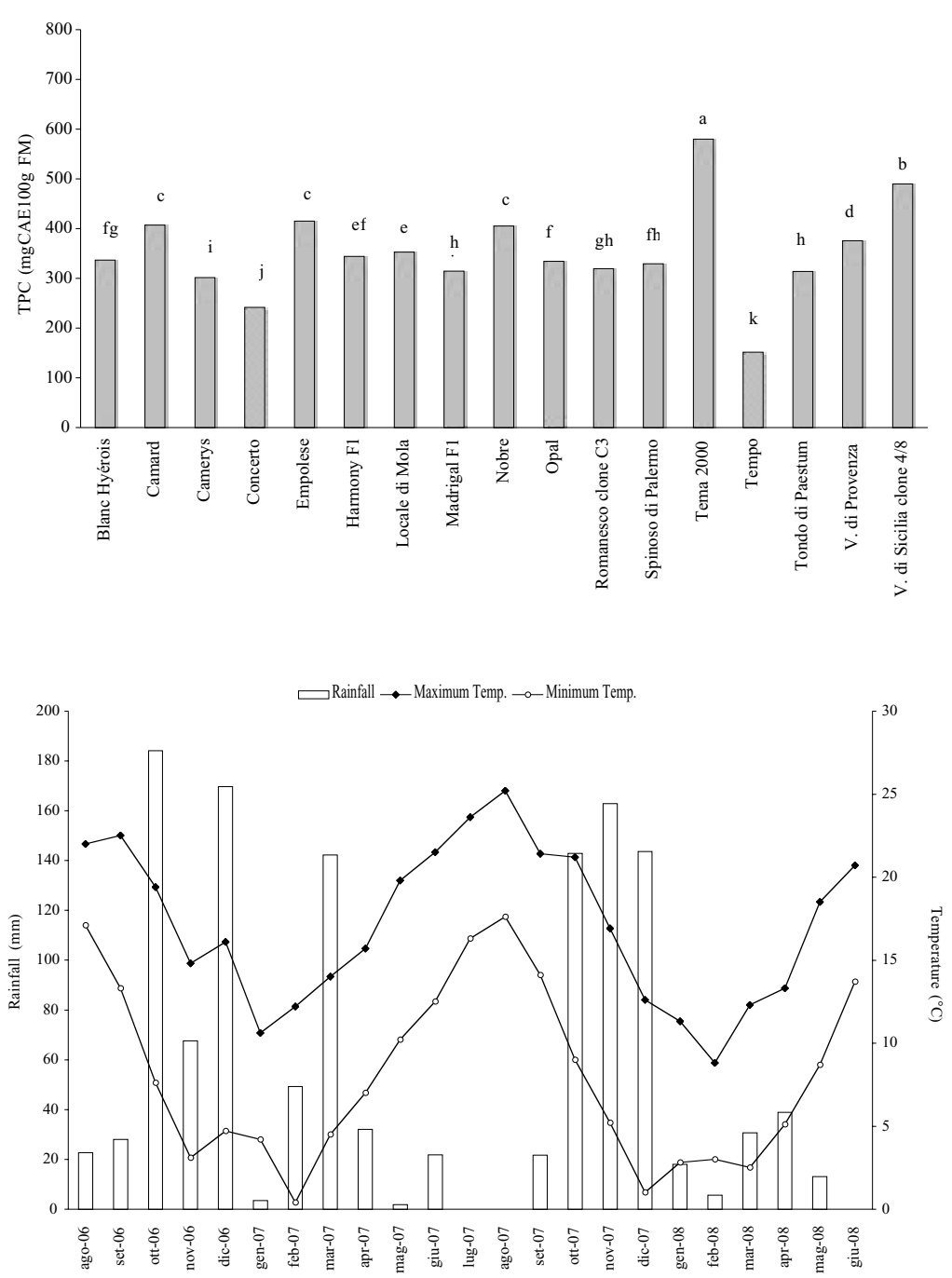

Figure 1. Trial A: Total polyphenols content (TPC) of the whole globe artichoke head as affected by genotype. Values are averages of two growing seasons. Different letters indicate statistical significance at $P \leq 0.05$.

Figure 2. Trial A: Rainfall and temperatures trends recorded during the period of the experiment. $14^{\circ} 11^{\prime} \mathrm{E}$ ), in a typic chomoxererts soil (USDA, Soil Taxonomy). A split-plot experimental design with four replications was adopted to test the effects of planting density $(1.0,1.2,1.4$ and 1.8 plant $\left.\mathrm{m}^{-2}\right)$ as main plot, and plant arrangement (single or twin rows) as sub-plot, on the total polyphenols content. "Violetto di Sicilia", an important and traditional Italian varietal type, was selected. Planting was performed in August 2006, using pre-sprouted "ovoli". Each experimental unit consisted of 40 plants. Starting fertilization was performed before planting with 70,150 and $120 \mathrm{~kg} \mathrm{ha}^{-1}$ of $\mathrm{N}, \mathrm{P}_{2} \mathrm{O}_{5}$ and $\mathrm{K}_{2} \mathrm{O}$, respectively. Two additional nitrogen applications, using as ammonium nitrate, were carried out at a rate of $65 \mathrm{~kg} \mathrm{ha}^{-1}$ in early November and late February, respectively. The further crop management practices (irrigation, pest management, etc.) were performed as per local customs.

\subsection{Sample preparation}

Heads, including the floral stem and the leaves joined to the latter, were harvested at the usual marketing stage, regardless of size. At this phase, the length of the central flower buds was about $2 \mathrm{~mm}$.

For analyses, 5 heads per plot were washed with tap water, dried and manually divided into 3 fractions: "other bracts" (10-15 external bracts), "inner bracts" (remaining bracts) and "receptacle". Then, an aliquot of each head part, previously blended, was lyophilized and stored at $-20{ }^{\circ} \mathrm{C}$ until HPLC-MS ${ }^{\mathrm{n}}$ analysis of polyphenols, whereas the remaining portion was assayed for analysis of total phenolics. 


\subsection{Chemicals}

Reagents and solvents of analytical grade, used for total polyphenols assays, were purchased from Sigma Aldrich (Milan, Italy), while those for HPLC analyses were purchased from VWR (Darmstadt, Germany) and were of analytical or HPLC grade. Apigenin 7-O-glucoside and 1,3-di- $O$-caffeoylquinic acid (cynarin) were from Roth (Karlsruhe, Germany); 5-O-caffeoylquinic acid (chlorogenic acid), luteolin 7 $O$-glucoside, and narirutin were obtained from Extrasynthése (Lyon, France); caffeic acid was purchased from Fluka (Buchs, Switzerland). Deionized water was used throughout.

\subsection{Total polyphenols}

For the extraction of phenolics, 5 grams of grounded tissue were treated with $50 \mathrm{ml}$ of methanol containing $1 \%$ hydrochloric acid, blended for 2 minutes in an Ultra-Turrax T18 (Janke \& Kunkel Ika-Labortechnik, Staufen, Germany) and stirred at room temperature for $1 \mathrm{~h}$. The filtrate (through Whatman No. 4 filter paper) was stored at $-20{ }^{\circ} \mathrm{C}$ until required. Each sample was extracted in duplicate.

The Folin-Ciocalteau assay (Singleton and Rossi, 1965) was used to quantify total polyphenols content. The absorbance was measured at $760 \mathrm{~nm}$ using a Shimadzu $1601 \mathrm{UV}$-Visible spectrophotometer. The total phenolic content was determined on the basis of a standard calibration curve generated with known amounts of chlorogenic acid. The results were expressed as milligrams of chlorogenic acid equivalent (CAE) per $100 \mathrm{~g}$ of fresh matter (FM).

\subsection{Quali-quantitative characterization of} polyphenols by $H P L C-M S^{n}$ analysis

The analyses, performed for "Romanesco clone C3", "Violetto di Provenza" and "Violetto di Sicilia" and limited to the samples harvested during the first growing season, were carried out as described previously by Schütz et al. (2004), using a series 1100 Hewlett-Packard HPLC (Waldbronn, Germany) equipped with binary gradient pump, diode array detection system and ChemStation software. A Phenomenex (Torrance, CA) $\mathrm{C}_{18}$ Hydro-Synergi column (4 $\mu \mathrm{m}$ particle size; $150 \times 3.0 \mathrm{~mm}$ i.d.), with a security guard $\mathrm{C}_{18}$ ODS column $(4 \times 3.0 \mathrm{~mm}$ i.d.), was used for peak separation, operating at $25{ }^{\circ} \mathrm{C}$.
Peak assignment was based on retention time of commercially available standards, analysing UV spectra and data obtained from HPLC-MS $^{\mathrm{n}}$ analyses. The latter were performed with the HPLC system described above coupled on-line with a Bruker (Bremen, Germany) model Esquire 3000+ ion trap mass spectrometer fitted with an ESI source. LC-MS parameters have been reported in detail by Schütz et al. (2004). For quantification, peak areas were correlated with the concentrations according to the calibration curve resulting from appropriate volumes of the standard stock solutions (1000 $\mathrm{mg} / \mathrm{L}$ ). Monocaffeoylquinic acids were calculated as chlorogenic acid, and dicaffeoylquinic acids were quantified as cynarin. Apigenin and luteolin derivatives were calculated as apigenin 7-O-glucoside and luteolin 7-O-glucoside, respectively. Naringenin 7-O-glucoside was calculated as narirutin. Herein, we reported the results of the whole capitulum. Data were expressed as $\mathrm{mg} \mathrm{kg}^{-1}$ of dry matter (DM). All analyses were performed in duplicate.

\subsection{Statistical Analysis}

All data were subjected to analysis of variance and means separated by Student-Newman-Keuls or LSD test, when the $F$-test was significant.

\section{Results}

\subsection{Trial A: Effects of genotype, head fraction and season conditions}

The total polyphenols content was affected by the factors under study (namely, genotype, head fraction and season conditions). The total phenolic content of the head was significantly accession-dependent. Regardless of season conditions and head fraction (Fig. 1), a high total phenolic content of the whole head was revealed by "Tema 2000" (580 mg CAE 100g-1 FM), followed by "Violetto di Sicilia clone 4/8" (489 mg CAE 100g-1 FM). "Empolese", "Camard" and "Nobre" also represented a rich source of these bio-compounds (on average, $409 \mathrm{mg}$ CAE $100 \mathrm{~g}^{-1}$ FM). The lowest total polyphenols concentrations were achieved by "Tempo" and "Concerto" (152 and $242 \mathrm{mg}$ CAE $100 \mathrm{~g}^{-1} \mathrm{FM}$, respectively). A phenolic content between 301 and 378 mg CAE $100 \mathrm{~g}^{-1} \mathrm{FM}$ was observed for ten accessions ("Violetto di Provenza", "Locale di 
Table 1. Trial A: Phenolic content ( $\mathrm{mg} \mathrm{kg}^{-1}$ of $\left.\mathrm{DM}\right)$ of the whole globe artichoke head in relation to genotype.

\begin{tabular}{lccc}
\hline Compound & \multicolumn{3}{c}{ Genotype } \\
\cline { 2 - 4 } & Romanesco clone C3 & Violetto di Provenza & Violetto di Sicilia \\
\hline 1 CQ ac & $19.6 \pm 1.0$ & $\mathrm{nd}^{(1)}$ & $259.4 \pm 14.4$ \\
$3 \mathrm{CQ}$ ac & $28.7 \pm 0.5$ & nd & $121.3 \pm 8.9$ \\
5 CQ ac & $131.2 \pm 11.5$ & $316.3 \pm 2.0^{(2)}$ & $6565.7 \pm 12.7$ \\
4 CQ ac & $51.7 \pm 1.5$ & $30.0 \pm 0.6$ & $265.3 \pm 10.1$ \\
Caf ac & $0.4 \pm 0.02$ & nd & nd \\
1,3 di CQ ac & $32.1 \pm 1.6$ & $36.7 \pm 2.7$ & $50.6 \pm 4.6$ \\
Lut rut & $10.0 \pm 0.6$ & $7.8 \pm 0.1$ & $63.1 \pm 9.0$ \\
Lut glc & $21.4 \pm 1.3$ & $8.3 \pm 1.2$ & $14.0 \pm 3.0$ \\
Lut glr & $570.0 \pm 11.5$ & $46.5 \pm 5.2$ & $169.6 \pm 11.9$ \\
Nar & $23.7 \pm 0.4$ & $29.7 \pm 1.1$ & $34.1 \pm 4.9$ \\
Nar glc & $18.4 \pm 1.0$ & $18.2 \pm 0.02$ & $10.2 \pm 1.4$ \\
di CQ & nd & nd & $70.2 \pm 5.4$ \\
3,4 di CQ ac & nd & $12.9 \pm 6.7$ & $152.3 \pm 27.9$ \\
3,5 di CQ ac & $76.9 \pm 15.6$ & $123.1 \pm 4.2$ & $1699.8 \pm 238.0$ \\
1,5 di CQ ac & $93.0 \pm 18.0$ & $129.7 \pm 23.9$ & $2884.4 \pm 341.6$ \\
Api rut & $157.6 \pm 7.2$ & $119.0 \pm 4.8$ & $77.6 \pm 14.3$ \\
Api glc & $604 \pm 3.4$ & $53.9 \pm 2.6$ & $100.9 \pm 23.6$ \\
Api glr & $2599.0 \pm 62.1$ & $841.0 \pm 0.6$ & $1073.3 \pm 28.4$ \\
4,5 di CQ ac & nd & $18.9 \pm 3.9$ & $5.3 \pm 0.1$ \\
\hline
\end{tabular}

(1) $\mathrm{nd}=$ not detected.

(2) Mean values \pm standard deviation

Note: $1 \mathrm{CQ}$ ac: 1 - $O$-caffeoylquinic acid $(\mathrm{Rt}=6.7 \mathrm{~min}) ; 3 \mathrm{CQ}$ ac: 3 - $O$-caffeoylquinic acid $(\mathrm{Rt}=8.9 \mathrm{~min}) ; 5 \mathrm{CQ}$ ac: 5 - $O$-caffeoylquinic acid (or chlorogenic acid) $(\mathrm{Rt}=17.5 \mathrm{~min}) ; 4 \mathrm{CQ}$ ac: 4 - $O$-caffeoylquinic acid $(\mathrm{Rt}=18.8 \mathrm{~min})$; Caf ac: caffeic acid $(\mathrm{Rt}=20.3 \mathrm{~min})$; 1,3 di CQ ac: 1,3 -di- $O$-caffeoylquinic acid (or cynarin) $(\mathrm{Rt}=31.7 \mathrm{~min})$; Lut rut: luteolin 7-O-rutinoside $(\mathrm{Rt}=49.8 \mathrm{~min})$; Lut glc: luteolin 7-O-glucoside $(\mathrm{Rt}=51.0 \mathrm{~min})$; Lut glr: luteolin 7- $O$-glucuronide $(\mathrm{Rt}=52.8 \mathrm{~min})$; Nar: narirutin $(\mathrm{Rt}=54.9 \mathrm{~min}) ; \mathrm{Nar}$ glc: naringenin 7- $O$-glucoside $(\mathrm{Rt}=58.8 \mathrm{~min})$; di CQ: dicaffeoylquinic acids $(\mathrm{Rt}=55.7 \mathrm{~min}) ; 3,4 \mathrm{di} \mathrm{CQ}$ ac: 3,4 -di- $O$-caffeoylquinic acid $(\mathrm{Rt}=58.4 \mathrm{~min}) ; 3,5 \mathrm{di} \mathrm{CQ}$ ac: 3,5-di- $O$-caffeoylquinic acid $(\mathrm{Rt}=62.5 \mathrm{~min}) ; 1,5 \mathrm{di} \mathrm{CQ}$ ac: 1,5 -di- $O$-caffeoylquinic acid $(\mathrm{Rt}=64.1$ $\mathrm{min})$; Api rut: apingenin 7-O-rutinoside $(\mathrm{Rt}=62.3 \mathrm{~min})$; Api glc: apigenin 7-O-glucoside $(\mathrm{Rt}=66.7 \mathrm{~min})$; Api glr: apigenin 7-Oglucuronide $(\mathrm{Rt}=71.6 \mathrm{~min})$; 4,5 di CQ ac: 4,5-di- $O$-caffeoylquinic acid $(\mathrm{Rt}=73.0 \mathrm{~min})$. $\mathrm{Rt}$, indicated in parenthesis, means retention time value.

Mola", "Harmony F,", "Blanc Hyèrois", "Opal”, "Spinoso di Palermo", "Romanesco clone $\mathrm{C}_{3}$ ", "Madrigal F,", "Tondo di Paestum" and "Camerys"). Concerning the individual phenolic compounds, significant differences among genotypes were found (Tab. 1). Regarding mono-caffeoylquinic acids, 'Violetto di Sicilia' reached the highest values for all the isomers detected (i.e. 1-, 3-, 5- and 4- $O$-caffeoylquinic acids). In particular, the high amount of chlorogenic acid (about $6566 \mathrm{mg} \mathrm{kg}^{-1} \mathrm{DM}$ ) was noteworthy, which represented about $91 \%$ of total mono-caffeoylquinic acids, considered as the sum of the above-cited phenolic compounds. With the only exception of 4,5-di- $O$-caffeoylquinic acid, slightly higher in "Violetto di Provenza" inflorescence, the other di-caffeoylquinic acids proved significantly higher in "Violetto di Sicilia", as already reported for mono-caffeoylquinic acids. In particular, "Violetto di Sicilia" achieved higher levels of 1,5and 3,5- di- $O$-caffeoylquinic acids (about 2884 and $1700 \mathrm{mg} \mathrm{kg}^{-1} \mathrm{DM}$, respectively). Caffeic acid was present in traces only in 'Romanesco clone C3' head.

Among the flavonoids, apigenin 7-O-glucuronide was the prevalent compound for all the genotypes studied, showing the highest amount in 'Romanesco clone C3' inflorescence (2599 $\left.\mathrm{mg} \mathrm{kg}^{-1} \mathrm{DM}\right)$. This cultivar also reached the highest concentrations $\left(158 \mathrm{mg} \mathrm{kg}^{-1}\right.$ of DM, respectively) of apigenin 7- $O$-rutinoside, as well as of luteolin $7-O$-glucuronide $\left(570 \mathrm{mg} \mathrm{kg}^{-1}\right.$ $\mathrm{DM})$. Luteolin 7-O-rutinoside was more abundant in 'Violetto di Sicilia' (63 $\mathrm{mg} \mathrm{kg}^{-1} \mathrm{DM}$ ), whereas luteolin 7-O-glucoside had low levels in all the genotypes under study. Narirutin and naringenin 7-O-glucoside were minor compounds of globe artichoke inflorescence.

Regardless of genotype and season (Fig. 3), the floral stem showed the highest total polyphenols content (557 mg CAE $100 \mathrm{~g}^{-1} \mathrm{FM}$ ), followed by receptacle (497 mg CAE $100 \mathrm{~g}^{-1}$ FM). The inner bracts recorded an intermediate 


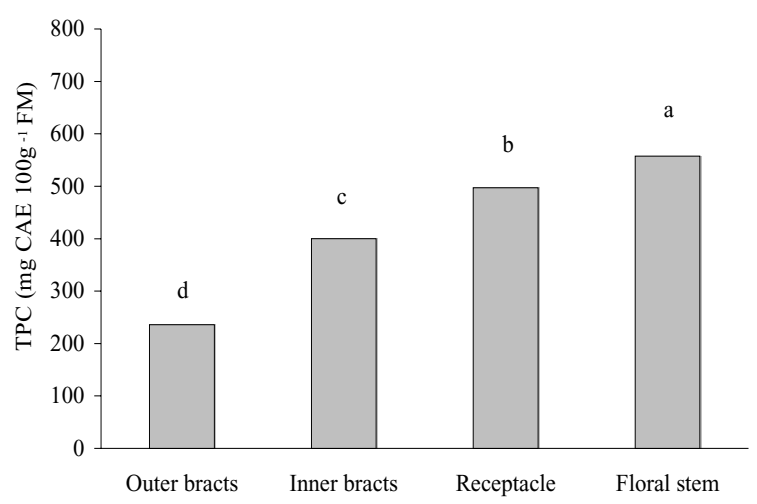

Figure 3. Trial A: Total polyphenols content (TPC) of globe artichoke as affected by head fraction. Different letters indicate statistical significance at $P \leq 0.05$.

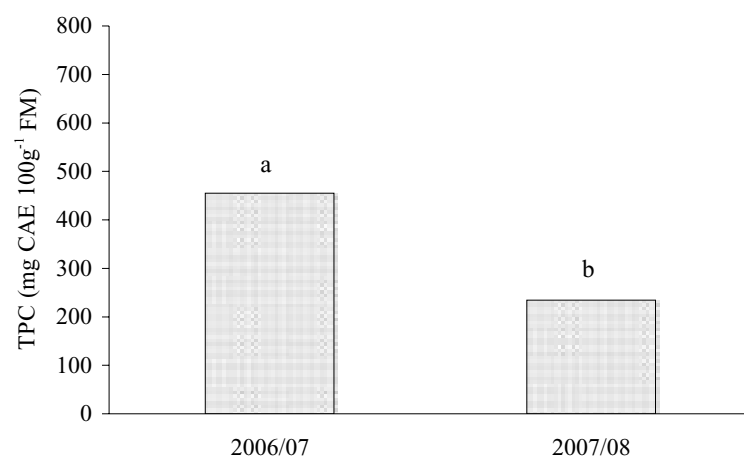

Figure 4. Trial A: Total polyphenols content (TPC) of the whole globe artichoke head as affected by season conditions. Different letters indicate statistical significance at $P \leq 0.05$. content (400 mg CAE $100 \mathrm{~g}^{-1} \mathrm{FM}$ ), whereas the outer bracts appeared to be the poorest fraction of the inflorescence (236 mg CAE $100 \mathrm{~g}^{-1} \mathrm{FM}$ ).

The total phenolic content of the whole head was also influenced by season conditions, resulting significantly higher in the first year than in second one ( 455 vs. $234 \mathrm{mg}$ CAE $100 \mathrm{~g}^{-1} \mathrm{FM}$; Fig. 4). Referring to the significant "season conditions $x$ genotype" interaction (Fig. 5), some accessions, such as "Tema 2000", "Violetto di Sicilia clone $4 / 8$ " and "Nobre", despite their richness in phenolics recorded in the first growing season, showed a significant reduction of the total polyphenols amount by 44,48 and $78 \%$, respectively (Fig. 5). On the contrary, "Camerys" $(+150 \%)$ achieved an appreciable increase of the total polyphenols level, passing from the first to the second year, whereas it was constant in "Tempo" inflorescence (Fig. 5).

\subsection{Trial B: Effects of technical practices}

The total polyphenols content increased from lower to higher planting density. This increase was linear and more marked for twin rows than for single ones (Tab. 2). The total phenolic level was also head parts dependent as demonstrated by the significance of "planting density $\mathrm{x}$ head parts" interaction (Tab. 3). Indeed, regardless of the planting arrangement, when passing from the lower to the higher plant density, the total phenolics increased by $108 \%$ for inner bracts, by $65 \%$ for leaves, by $52 \%$ for floral stem and by $14 \%$ for both other bracts and
Figure 5. Trial A: Total polyphenols content (TPC) of the whole globe artichoke head as affected by season conditions and genotype. Different letters indicate statistical significance at $P \leq 0.05$.

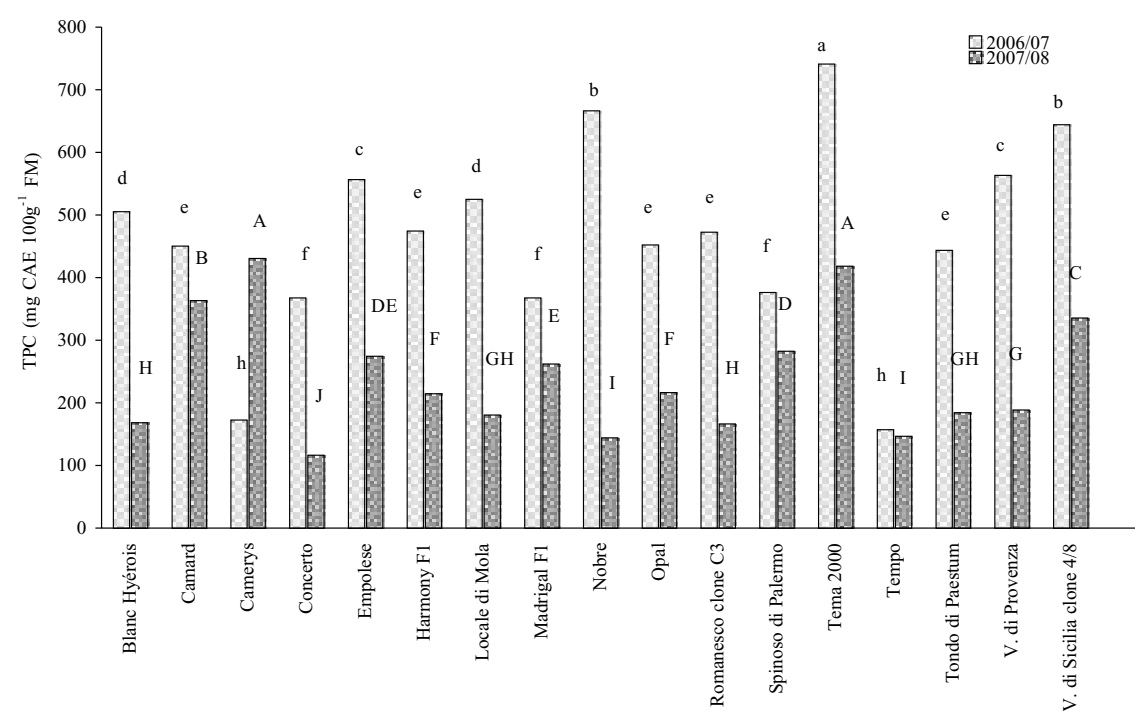


Table 2. Trial B: Total polyphenols content (TPC) of the whole globe artichoke head in relation to plant arrangements and planting density.

\begin{tabular}{|c|c|c|c|c|c|}
\hline \multirow{3}{*}{$\begin{array}{l}\text { Plant arrangement } \\
(\mathrm{Pa})\end{array}$} & \multicolumn{4}{|c|}{ Planting density (Pd) } & \multirow{3}{*}{ Mean } \\
\hline & \multicolumn{4}{|c|}{$n m^{-2}$} & \\
\hline & 1.0 & 1.2 & 1.4 & 1.8 & \\
\hline & \multicolumn{4}{|c|}{$m g C A E 100 g^{-1} F M$} & \\
\hline Single rows & 482 & 486 & 482 & 553 & 501 \\
\hline Twin rows & 406 & 501 & 567 & 790 & 566 \\
\hline Mean & 444 & 493 & 524 & 671 & $\mathrm{~L}^{* * *} \mathrm{Q}^{\mathrm{NS}}$ \\
\hline
\end{tabular}

LSD $(P \leq 0.05) \mathrm{Pa}=53 ; \mathrm{Pd}=75 ; \mathrm{Pa} \times \mathrm{Pd}$ interaction $=105 ; \mathrm{L}=$ linear; $\mathrm{Q}=$ quadratic; $* * *$ and NS indicate, respectively, significant $P \leq 0.001$, and not significant to regression analysis.

Table 3. Trial B: Total polyphenols content (TPC) of globe artichoke in relation to planting density and head parts.

\begin{tabular}{|c|c|c|c|c|c|}
\hline \multirow{2}{*}{$\begin{array}{l}\text { Planting density } \\
(\mathrm{Pd})\end{array}$} & \multicolumn{5}{|c|}{ Head parts (Hp) } \\
\hline & Leaves & Other bracts & Inner bracts & Receptacle & Floral stem \\
\hline$n m^{-2}$ & \multicolumn{5}{|c|}{$m g C A E 100 g^{-1} F M$} \\
\hline 1,0 & 461 & 296 & 404 & 504 & 556 \\
\hline 1,2 & 429 & 293 & 599 & 465 & 681 \\
\hline 1,4 & 723 & 274 & 629 & 550 & 448 \\
\hline 1,8 & 759 & 338 & 839 & 576 & 846 \\
\hline Mean & 593 & 300 & 618 & 524 & 633 \\
\hline $\mathrm{L}$ & $* * *$ & $* * *$ & $* * *$ & $* * *$ & $* * *$ \\
\hline Q & NS & $*$ & $* *$ & NS & $* *$ \\
\hline
\end{tabular}

LSD $(P \leq 0.05) \mathrm{Pd}=75 ; \mathrm{Hp}=83 ; \mathrm{Pd} \times \mathrm{Hp}$ interaction $=167 ; \mathrm{L}=$ linear; $\mathrm{Q}=$ quadratic; $* * *, * * *$ and NS indicate, respectively, significant at $P \leq 0.05, P \leq 0.01, P \leq 0.001$, and not significant to regression analysis.

receptacle. As regards the plant arrangements (Tab. 2), the total polyphenols content was higher in twin rows than in single ones (566 vs. 501 mg CAE $100 \mathrm{~g}^{-1} \mathrm{FM}$ ).

Irrespective of planting arrangement and density (Tab. 3), the floral stem and inner bracts yielded a higher total phenolic amount (633 and 618 mg CAE $100 \mathrm{~g}^{-1} \mathrm{FM}$, respectively) than other parts of the inflorescence. A rather high polyphenolic content value was also found for the leaves (593 $\mathrm{mg}$ CAE $\left.100 \mathrm{~g}^{-1} \mathrm{FM}\right)$. The total polyphenols in receptacle, although appreciable (524 $\mathrm{mg}$ CAE $100 \mathrm{~g}^{-1} \mathrm{FM}$ ), was statistically lower compared to the other fractions mentioned. A significantly lower value for the content of these bio-molecules was recorded for the other bracts $(300 \mathrm{mg}$ CAE $\left.100 \mathrm{~g}^{-1} \mathrm{FM}\right)$.

\section{Discussion}

The results obtained in the present study have provided useful information about the effects of some biotic and abiotic factors on the content of phenolic compounds in the globe artichoke inflorescence. Firstly, a significant and consistent influence of genotype was found on the content of both total polyphenols and individual phenolic compounds as previously reported in other crops, including strawberry (Tulipani et al., 2008), fig (Veberic et al., 2008), potato (Andre et al., 2007) and pome fruits (Imeh and Khokhar, 2002). Our results on the total polyphenols content of artichoke inflorescence were, on the whole, comparable with those previously reported by Alamanni and Cossu (2003) for "Spinoso sardo" edible fraction (589 mg $100 \mathrm{~g}^{-1} \mathrm{FM}$ ), whereas they were slightly lower than results reported by Curadi et al. (2005). In the latter case, the differences may largely be related to the different type of material analysed (inner bracts or whole head), developmental stage and environmental conditions. Comparison with other available data is still dif- 
ficult because different analytical methods, including several calibration standards and ways of expressing phenolic concentration, have been applied in literature.

Moreover, our findings may allow to select cultivars for specific uses, since accessions characterized by high total polyphenols content (i.e. "Tema 2000" and "Violetto di Sicilia clone 4/8") are probably more suitable for fresh consumption or for the commercial extraction of natural anti-oxidants, whereas those with low content of phenolics, as well as "Tempo" and "Concerto", are potentially more appropriate for food processing because of their supposed less proneness to browning reactions during handling and storage (Lattanzio et al., 1994; Lattanzio, 2003).

Additional HPLC analysis of phenolic compounds, although limited to only three accessions, has revealed a qualitatively and quantitatively different profile of these biomolecules in relation to genotype. The high level of chlorogenic and 4- $O$-caffeoylquinic acids, among the mono-caffeoylquinic acids, and of 1,5- and 3,5-di- $O$-caffeoylquinic acids, among the di- $O$-caffeoylquinic acids, reported by "Violetto di Sicilia", an inland varietal type, suggest promoting its consumption on a wider scale. According to previous studies (Schütz et al., 2004; Lombardo et al., 2009), the high amount of the above-mentioned di-caffeoylquinic acids could be attributed to isomerization reactions of 1,3-di- $O$-caffeoylquinic acid (cynarin), that reached low levels in all the genotypes considered in the present study. In contrast, "Romanesco clone C3" proved to be an interesting source of apigenin derivatives. Such findings may be interesting in consideration that these compounds, among others, are responsible for the antispasmodic and anti-inflammatory activity of chamomile preparations (Carle and Gomaa, 1992). Thus, additional studies confirming similar effects in artichoke may be of interest.

Phenolic content was also affected by head fraction. In particular, given the enhanced interest for "functional" foods by consumers, the demonstrated richness of phenolic compounds in the receptacle, considered as the main edible part of the plant, may be used to encourage artichoke consumption on a wider scale. At the same time, the floral stem, generally not considered edible and discarded as a waste product, may represent an unexploited source of nutraceutical compounds and an alternative source of revenue for the producers and processors
(Lattanzio et al., 2001; Peschel et al., 2006). Moreover, our findings confirmed an inverse relationship between phenolic content and tissue age; therefore, as predicted, the other bracts contained the least total phenolics, reaching on average only $65 \%$ of the amount present in the inner bracts. Further analyses are still necessary in order to assess the specific behaviour of each accessions under study, since this could allow selecting artichoke cultivars for more specific uses (fresh consumption, food processing, etc.).

As highlighted by the results acquired, although the level of phenolic compounds is strictly under genetic control, it could be subjected to marked and significant variations in relation also to meteorological conditions, resulting from differing growing seasons, and technical practices adopted. Basically, the different weather conditions recorded during the harvest period of the first growing season, represented mainly by the highest average maximum temperatures and the greater quantity of rainfall, are presumably more favorable to phenolics bio-synthesis for the most of genotypes, with the exception of "Tempo" and "Camerys".

The higher phenolic contents reached at the higher planting density and in twin rows may be induced by the enhanced intraspecific competition. In this light, the quantification of total phenolic fraction of artichoke heads has allowed acquiring the most interesting results related to the biochemical response of plants to the level of intraspecific competition. Indeed, some phenolics, such as quinones, simple phenols, phenolic acids, cinnamic derivatives and flavonoids, among their functions, may also act as allelopathic agents, exerting an inhibitory effect on both the germination of seeds and the growing process of plants. They may also influence the availability, the absorption speed and the accumulation of many mineral nutrients in the soil.

Further researches are still necessary to obtain deeper insights into the other factors (i.e. cultivation environment, crop management practices, harvest time, etc.) that may affect polyphenols biosynthesis and accumulation in artichoke plants, so that it might be possible to ascertain the plasticity of phenolic content in response to the variation of such factors. However, additional studies to define the phenolic profile of other artichoke cultivars qualitatively and quantitatively are still required to fully exploit Italian artichoke germplasm for specific uses. 


\section{Acknowledgements}

The authors are grateful to Professor R. Carle and Dr. M. Knödler, from Hohenheim University (Germany), and to Professor A. Schieber, from Alberta University (Canada), for the opportunity to perform part of the experimental work (HPLC-MS ${ }^{\mathrm{n}}$ analyses) at Hohenheim University, Institute of Food Science and Biotechnology - Chair Plant Foodstuff Technology. This work was partially funded by M.O.T.I.C.I. Project (Regione Siciliana - Assessorato Agricoltura e Foreste).

\section{References}

Alamanni M.C., Cossu M. 2003. Antioxidant activity of the extracts of the edible part of artichoke (Cynara scolymus L.) var. Spinoso sardo. Ital. J. Food Sci., 15, 2:187-195.

Andre C.M., Ghislain M., Bertin P., Oufir M., Del Rosario Herrera M., Hoffmann L., Hausman J.F., Larondelle Y., Evers D. 2007. Andean potato cultivars (Solanum tuberosum L.) as a source of antioxidant and mineral micronutrients. J. Agric. Food Chem., 55:366-378.

Beckman C.H. 2000. Phenolic-storing cells: keys to programmed cell death and periderm formation in wilt disease resistance and in general defence responses in plants?. Physiol. Mol. Plant Pathol., 57:101-110.

Brat P., Georgè S., Bellamy A., Du Chaffaut L., Scalbert A., Mennen L., Arnault N., Amiot M.J. 2006. Daily polyphenol intake in France from fruit and vegetables. J. Nutr., 136:2368-2373.

Brown J.E., Rice-Evans C.A. 1998. Luteolin-rich artichoke extract protects low density lipoprotein from oxidation in vitro. Free Rad. Res., 29:247-255.

Carle R., Gomaa K. 1992. Chamomile: A pharmacological and clinical profile. Drugs Today, 28:559-565.

Curadi M., Ceccarelli N., Graifenberg A., Picciarelli P. 2004. Composti ad attività antiossidante nei capolini di carciofo: differenze varietali. Italus Hortus, 11, 5:81-84.

Curadi M., Picciarelli P., Lorenzi R., Graifenberg A., Ceccarelli N. 2005. Antioxidant activity and phenolic compounds in the edible parts of early and late Italian artichoke (Cynara scolymus L.) varieties. Ital. J. Food Sci., 17, 1:33-44.

FAO Statistical Database 2009: http://www.faostat.org/.

Falleh H., Ksouri R., Chaieb K., Karray-Bouraoui N., Trabelsi N., Boulaaba M., Abdelly C. 2008. Phenolic composition of Cynara cardunculus L. organs, and their biological activities. C. R. Biologies, 331:372-379.

Gebhardt R. 1997. Antioxidative and protective properties of extracts from leaves of the artichoke against hydroperoxide-induced oxidative stress in cultured rat hepatocytes. Toxicol. Appl. Pharm., 144:279-286.

Imeh U., Khokhar S. 2002. Distribution of conjugated and free phenols in fruits: Antioxidant activity and cultivar variations. J. Agric. Food Chem., 50:6301-6306.

Lattanzio V., Van Sumere C.F. 1987. Changes in phenolic compounds during development and cold storage of artichoke (Cynara scolymus L.). Food Chem., 24:37-50.

Lattanzio V., Cardinali A., Di Venere D., Linsalata V., Palmieri S. 1994. Browning phenomena in stored artichoke (Cynara scolymus L.) heads: enzymatic or chemical reactions? Food Chem., 50:1-7.

Lattanzio V., Cicco N., Terzano R., Raccuia S., Mauromicale G., Di Venere D., Linsalata V. 2001. Potenziale utilizzo di sottoprodotti derivanti dalla lavorazione industriale del carciofo [Cynara cardunculusi L. var. scolymus (L.) Fiori]: antiossidanti di natura fenolica ed inulina. Proceedings XIX Convegno SICA, 25-28 September, Reggio Calabria, Italia, 251-258.

Lattanzio V. 2003. Bioactive polyphenols: their role in quality and storability of fruit and vegetables. J. Appl. Bot., 77:128-146.

Lombardo S., Pandino G., Mauromicale G., Knödler M., Carle R., Schieber A. 2009. Influence of genotype, harvest time and plant part on polyphenolic composition of globe artichoke [Cynara cardunculus L. var. scolymus (L.) Fiori]. Food Chem. (2009), doi: 10.1016/j.foodchem.2009.08.033

Mauromicale G., Ierna A. 2000. Panorama varietale e miglioramento genetico del carciofo. Inform. Agrar., 56:39-45.

Naczk M., Shahidi F. 2006. Phenolics in cereals, fruits and vegetables: occurrence, extractions and analysis. J. Pharmaceutic. Biomed, 41:1523-1542.

Peschel W., Sànchez-Rabaneda F., Diekmann W., Plescher A., Gartzìa I., Jimènez R., Lamuela-Raventòs D., Buxaderas S., Codina C. 2006. An industrial approach in the search of natural antioxidants from vegetable and fruit wastes. Food Chem., 97:137-150.

Racchi M., Daglia M., Lanni C., Papetti A., Govoni S., Gazzani G. 2002. Antiradical activity of water soluble components in common diet vegetables. J. Agric. Food Chem., 50:1272-1277.

Schütz K., Kammerer D., Carle R., Schieber A. 2004. Identification and quantification of caffeoylquinic acids and flavonoids from artichoke (Cynara scolymus L.) heads, juice, and pomace by HPLC-DADESI/MS ${ }^{n}$. J. Agric. Food Chem., 52:4090-4096.

Singleton V.L., Rossi J.A. Jr. 1965. Colorimetry of total phenolics with phosphomolybdic phosphotungstic acid reagents. Amer. J. Enol. Vitic., 16:144-158.

Tulipani S., Mezzetti B., Capocasa F., Bompadre S., Beekwilder J., De Vos C.H.R., Capanoglu E., Bovy A., Battino M. 2008. Antioxidants, phenolic compounds, and nutritional quality of different strawberry genotypes. J. Agric. Food Chem., 56:696-704.

Veberic R., Colaric M., Stampar F. 2008. Phenolic acids and flavonoids of fruits (Ficus carica L.) in the northern Mediterranean region. Food Chem., 106:153-157.

Wang M., Simon J.E., Aviles I.F., He K., Zheng Q., Tadmor Y. 2003. Analysis of antioxidative phenolic compounds in artichoke (Cynara scolymus L.). J. Agric. Food Chem., 51:601-608. 